\title{
Prevalence and correlates of multiple non- communicable diseases risk factors among adults in Sudan: Results of the first national STEPS survey in 2016
}

\section{Supa Pengpid}

Mahidol University

Karl Peltzer ( $\boldsymbol{D}$ kfpeltzer@gmail.com )

University of the Free State https://orcid.org/0000-0002-5980-0876

Research article

Keywords: multiple non-communicable diseases, sociodemographic factors, adults, Sudan

Posted Date: August 11th, 2020

DOI: https://doi.org/10.21203/rs.3.rs-48950/v1

License: (c) (i) This work is licensed under a Creative Commons Attribution 4.0 International License.

Read Full License 


\section{Abstract \\ Background}

Non-communicable diseases (NCDs) are on the rise in low- and middle-income countries. The aim of this study was to assess the prevalence and correlates of multiple NCD risk factors among adults in Sudan.

\section{Methods}

Cross-sectional nationally representative data were analysed from 7,722 18-69 year-old individuals (median age $=36$ years) that took part in the "2016 Sudan STEPS survey."

\section{Results}

The prevalence of individual NCD risk factors was $94.6 \%$ inadequate fruit and vegetable intake, followed by hypertension (31.6\%), general overweight/obesity (28.0\%), low physical activity (21.3\%), current tobacco use (15.7\%), raised total cholesterol (13.6\%), diabetes (5.9\%), and heavy episodic drinking (1.7\%). In all, $34.2 \%$ had $0-1$ NCD risk factor, $33.5 \% 2$ risk factors, and $32.4 \% 3$ or more NCD risk factors. In adjusted ordinal logistic regression analysis, compared to individuals 18-34 years old, persons 5069 years old were 3.52 times (AOR: $3.52,95 \%$ Cl: $2.88-4.31$ ) more likely to have multiple NCD risk factors. Men were $21 \%$ (AOR: $1.21,95 \%$ Cl: $1.00-1.46$ ) more likely than women to have multiple NCD risk factors. Individuals residing in urban areas were $86 \%$ (AOR: $1.86,95 \% \mathrm{Cl}: 1.49-2.32$ ) more likely than individuals residing in rural areas to have multiple NCD risk factors, and compared to persons never married, married participants and persons separated, divorced or widowed persons were 51\% (AOR: 1.51, 95\% Cl: 1.221.87) and 74\% (AOR: $1.74,95 \% \mathrm{Cl}: 1.22-2.47$ ), respectively, more likely to have multiple NCD risk factors. Compared to persons with less than 500 pounds household income, persons with over 2000 pounds household income were $75 \%$ (AOR: $1.75,95 \% \mathrm{Cl}$ : 1.28-2.38) more likely to have multiple NCD risk factors. Compared to women who cannot read or write, women who had more than primary education were $38 \%$ (AOR: $1.38,95 \% \mathrm{Cl}$ : 1.06-1.80) more likely to have multiple NCD risk factors. Compared to men who were self-employed, engaged in non-paid work, were students or unemployed (able to work), government employees, non-government employees, retired or unemployed (unable to work) had a significantly higher odds of having multiple NCD risk factors.

\section{Conclusion}

Almost one in three participants had three or more NCD risk factors and several associated variables were identified that can facilitate in designing intervention programmes.

\section{Background}


Non-communicable diseases (NCDs) are "estimated to account for $52 \%$ of all deaths in Sudan in 2016 " [1]. More than $85 \%$ of NCD "premature" deaths occur in low- and middle-income countries [2]. Cardiovascular diseases, cancers, respiratory diseases, and diabetes contribute to over $80 \%$ of all premature NCD deaths [2]. Poor diets, tobacco use, harmful alcohol use, and low physical activity all increase the risk of dying from a NCD [2]. In the rapid increase of NCDs in sub-Saharan Africa and the Eastern Mediterranean region, it is "crucial to have a careful understanding of the local drivers of NCDs" $[3,4]$. There is lack of national data on the prevalence of multiple NCD risk factors and associated factors among adults in community-based surveys in Sudan, a low-income country geographically in subSaharan Africa. Some population-based studies among adults in Sudan were sub-national and only focused on specific NCD risk factors, such as the prevalence of overweight/obesity was $56.1 \%$ in four states (Khartoum, Gezira, Blue Nile, and Kassala) [5], 59.0\% in Gadarif, Eastern Sudan [6], hypertension was $16.6 \%$ in four states (Khartoum, Gezira, Blue Nile, and Kassala) [7], 40.8\% in Gadarif, Eastern Sudan [8], the $35.7 \%$ in four main cities of the River Nile State, north Sudan [9], 23.6\% in the 2005-2006 Khartoum State STEPS survey [10], and $27.6 \%$ in Khartoum State in Sudan [11]. The prevalence of diabetes was $19.1 \%$ in four main cities of the River Nile State, north Sudan [12], 18.7\% in the Northern State and River Nile State [13], and 19.8\% in the 2005-2006 Khartoum State STEPS survey [10]. In a community-based study in Khartoum state, Sudan, the prevalence of physical inactivity was $53.8 \%$ [14], the prevalence of current smoking was $12.0 \%$ in the 2005-2006 Khartoum State STEPS survey [10], and in a cross-sectional survey of 403 households in Kassala State, Sudan, $72.8 \%$ and $36.2 \%$ rarely or did not consume fruit and vegetables, respectively [15].

In the 2015 Kenya STEPS survey (18-69 years), 75.8\% had 4-12 NCD risk factors (high blood total cholesterol: $10.1 \%$, low blood HDL cholesterol: $57.7 \%$, high sugar intake: $14.9 \%$, inadequate fruit and vegetable intake: $99.8 \%$, obesity: $22.4 \%$, low physical activity: $89.3 \%$, bad fat intake: $39.8 \%$, high intake of salt: $89.5 \%$, hypertension: $24.8 \%$, diabetes: $2.6 \%$, smoking: $10.2 \%$, and harmful alcohol use: $13.8 \%$ ) [16]. In the 2009 Malawi STEPS survey (24-64 years), 16.5\% had 3-7 NCD risk factors (raised blood pressure: $32.9 \%$, raised fasting blood glucose: $5.6 \%$, raised cholesterol: $8.7 \%$, overweight or obesity: $26.5 \%$, tobacco smokers: $14.1 \%$, excessive alcohol drinkers: 7.7\%, and low physical activity: 9.5\%) [17]. In the 2014 Uganda STEPS survey (18-69 years), $17.3 \%$ had 3-5 NCD risk factor (daily tobacco use, five servings fruit and vegetables, low physical activity, high body mass index and raised blood pressure) [18]. In the 2013 Nepal STEPS survey (15-69 years), 27.7\% had 3-8 NCD risk factors (current smoking: 18.5\%, harmful alcohol use: $2.0 \%$, inadequate fruit and vegetable intake: $98.9 \%$, low physical activity: $3.4 \%$, overweight or obesity: $21.4 \%$, raised blood pressure: $25.7 \%$, raised blood glucose: $3.6 \%$, and raised total cholesterol: 22.6\%) [19].

Factors associated with multiple behavioural and biological NCD risk factors include older age [16, 1922], men [19, 20], currently married [19], geographic region [18, 19], less than higher education [19], higher level of education [20], type of residence [18], better quality of housing [20], higher income level [22], salaried employment [22], and urban residence [20, 22]. The investigation aimed to estimate the prevalence and correlates of multiple NCD risk factors among 18-69 year-old persons in Sudan. 


\section{Methods}

A four-stage stratified cluster sampling method was used to generate representative data of adults aged 18 to 69 years in the cross-sectional Sudan STEPS Survey in 2016, more details of the sample design [23]. A total of 7,722 individuals (Median age=36 years; IQR: 23-43) participated in the study. Information on socio-demographic and behavioural NCD risk factors was gathered in Step 1 [23]. "Physical measurements such as height, weight and blood pressure were collected in Step 2" [23]. "Biochemical measurements were collected to assess blood glucose and cholesterol levels in Step 3" [23].

Respondents' responses were recorded by the survey administrator on survey tablets (Samsung tablet 4) [23]. Blood glucose and cholesterol were measured using cardio-check examination equipment (Cardio check P.A. In vitro diagnostic medical devices for use with PTS panels test strips; Manufacturer: Polymer Technology Systems, INC, Indianapolis, IN USA CE 0197) [23]. The response rate for STEP 1 and 2 was 95\%, and for STEP $388 \%$ [23].

\section{Measures}

Outcome variables: NCD risk factors

Behavioural NCD risk behaviour variables included inadequate fruit and vegetable intake $(<5$ servings/day), low physical activity based on the "Global Physical Activity Questionnaire", current tobacco use (smoking and/or smokeless tobacco), and episodic heavy alcohol use (six or more in one session) in the past months [23].

Biological NCD risk factors. Fasting ( $\geq 10$ hours) blood sugar measurements were conducted and diabetes was defined as "fasting plasma glucose levels $\geq 7.0 \mathrm{mmol} / \mathrm{L}$, and/or currently taking insulin or oral hypoglycemic drugs." [23] Hypertension was assessed based on measured blood pressure (BP) (mean of the last two of three readings) defined as systolic BP $\geq 140 \mathrm{~mm} \mathrm{Hg}$ and/or diastolic BP $\geq 90$ $\mathrm{mm} \mathrm{Hg}$ or currently on antihypertensive medication; raised total cholesterol (TC) ("fasting TC $\geq 5.0$ $\mathrm{mmol} / \mathrm{L}$ or currently on medication for raised cholesterol"); Body Mass Index (measured $25-29.9 \mathrm{~kg} / \mathrm{m}^{2}$ overweight and $\geq 30 \mathrm{~kg} / \mathrm{m}^{2}$ obesity) [23].

Exposure variables included, sex, age, work status, education, household income, residence status and marital status [23].

\section{Data analysis}

Statistical analyses were conducted with "STATA software version 15.0 (Stata Corporation, College Station, Texas, USA)," considering the complex study design. All results were weighted by age and sex categories." [23] The number of NCD risk factors (10) were classified into three groups, 1=0-1, $2=2$ and 3=3-8 NCD risk factors, and described with frequency counts and bar graphs. Unadjusted and adjusted ordered logistic regression were used to assess predictors of one or more NCD risk factors. Missing values were not included in the analysis. $\mathrm{P}<0.05$ was accepted as significant. 


\section{Results}

\section{Sample and NCD risk factor characteristics}

The sample included 7,722 adults (35.1\% males and $64.9 \%$ females) aged 18 to 69 years, median age 31 years (IQR: 23-43). About one-third of the participants (34.0\%) could not read and write, $51.7 \%$ had an household income of 1000 or less Sudanese pounds, and $62.9 \%$ were residing in rural areas.

The prevalence of individual NCD risk factors was $94.6 \%$ inadequate fruit and vegetable intake, followed by hypertension (31.6\%), general overweight/obesity (28.0\%), low physical activity $(21.3 \%)$, current tobacco use (15.7\%), raised total cholesterol (13.6\%), diabetes (5.9\%), and heavy episodic drinking (1.7\%). The prevalence of tobacco use and heavy episodic drinking was significantly higher in men than in women, while low physical activity, general overweight/obesity, raised total cholesterol and diabetes was significantly higher in women than in men (Table 1).

\section{Frequency distribution of multiple NCD risk factors}

The prevalence of having zero NCD risk factors was $1.5 \%, 1$ risk factor $32.6 \%, 2$ risk factors $33.5 \%, 3$ risk factors $19.9 \%, 4$ risk factors $9.3 \%, 5$ risk factors $2.8 \%, 6$ risk factors $0.3 \%, 7$ risk factors $0.1 \%$ and 8 risk factors $0 \%$ (Figure 1 ).

Overall, $34.2 \%$ had 0-1 NCD risk factor, 33.5\% 2 risk factors, 32.4\% 3-8 NCD risk factors. Having multiple NCD risk factors increased with age, urban residence, higher education, higher household income, marital and employment status and sex (Table 2).

\section{Associations with multiple NCD risk factors}

In adjusted ordinal logistic regression analysis, compared to individuals 18-34 years old, persons 50-69 years old were 3.52 times (AOR: $3.52,95 \% \mathrm{Cl}$ : 2.88-4.31) more likely to have multiple NCD risk factors. Men were $21 \%$ (AOR: $1.21,95 \% \mathrm{Cl}$ : 1.00-1.46) more likely than women to have multiple NCD risk factors. Individuals residing in urban areas were $86 \%$ (AOR: 1.86, 95\% Cl: 1.49-2.32) more likely than individuals residing in rural areas to have multiple NCD risk factors, and compared to persons never married, married participants and persons separated, divorced or widowed persons were 51\% (AOR: 1.51, 95\% Cl: 1.221.87 ) and $74 \%$ (AOR: $1.74,95 \% \mathrm{Cl}: 1.22-2.47$ ), respectively, more likely to have multiple NCD risk factors. Compared to persons with less than 500 pounds household income, persons with over 2000 pounds household income were $75 \%$ (AOR: $1.75,95 \% \mathrm{Cl}$ : 1.28-2.38) more likely to have multiple NCD risk factors. Compared to women who cannot read or write, women who had more than primary education were $38 \%$ (AOR: $1.38,95 \% \mathrm{Cl}: 1.06-1.80)$ more likely to have multiple NCD risk factors. Compared to men who were self-employed, engaged in non-paid work, were students or unemployed (able to work), government employees, non-government employees, retired or unemployed (unable to work) had a significantly higher odds of having multiple NCD risk factors (Table 3 ). 


\section{Discussion}

The present study aimed to assess the prevalence and correlates of multiple NCD risk factors in a national community-based survey among 18-69 year-old individuals in Sudan. The prevalence of 3-8 NCD risk factors $(32.4 \%)$ in this study (18-69 years) was higher than in the 2009 Malawi STEPS survey (24-64 years) (16.5\% 3-7 NCD risk factors) [17], the 2014 Uganda STEPS survey (18-69 years) (17.3\% 3-5 NCD risk factors) [18], the 2013 Nepal STEPS survey (15-69 years) (27.7\% 3-8 NCD risk factors [19], and lower than in the 2015 Kenya STEPS survey (18-69 years) (75.8\% 4-12 NCD risk factors [16]. The clustering of three of more NCD risk factors was common in this survey predisposing the adult population in Sudan to a greater risk of NCDs.

In agreement with some studies [16, 19-22], this study showed that older age, male sex, being married, urban residence, higher household income, being in salaried employment, and among women higher education increased the odds for multiple NCD risk factors. Regarding increasing age, early screening, in particular among males, those with higher income, higher education and residing in urban areas, should be propagated to prevent an accumulation of NCD risk factors in Sudan.

Regarding individual NCD risk factors, the four most prevalent were inadequate fruit and vegetable intake (94.6\%), hypertension (31.6\%), overweight/obesity (28.0\%), and low physical activity (21.3\%). Similar results were found in the Kenya [16] and Nepal [19] STEPS surveys. The prevalence of hypertension was higher than in previous three local surveys, in four states (Khartoum, Gezira, Blue Nile, and Kassala) (16.6\%) [7], in the 2005-2006 Khartoum State SEPS survey (23.6\%) [10], and in Khartoum State in Sudan (27.6\%) [11], but lower than in two other local surveys in Gadarif, Eastern Sudan (40.8\%) [8], and in four main cities of the River Nile State, north Sudan (35.7\%) [9]. The prevalence of overweight/obesity (28.0\%) was lower than in four states (Khartoum, Gezira, Blue Nile, and Kassala) (56.1\%) [5], and in Gadarif, Eastern Sudan (59.0\%) [6]. The high prevalence of inadequate fruit and vegetable intake (94.6\%) in this survey was also found in a community in Kassala State, Sudan $(72.8 \%$ and $36.2 \%$ rarely or did not consume fruit and vegetables, respectively) [15]. The 2016 Sudan STEPS survey team recommend to "strengthen health literacy and capacity of individuals to make healthy choices e.g. by making fruits and vegetable more affordable" [23].

The prevalence of current tobacco use (15.7\%) and heavy episodic alcohol use (1.7\%) in this study was in terms of tobacco use similar to the 2005-2006 Khartoum State STEPS survey (current smoking 12.0\%) [10], the Kenya STEPS survey (smoking: 10.2\%) [16] and the Malawi STEPS survey (tobacco smokers: $14.1 \%$ ) [17] but lower in terms of heavy drinking in the Kenya STEPS survey (harmful alcohol use: 13.8\%) [16] and the Malawi STEPS survey (excessive alcohol drinkers: 7.7\%) [17]. Increasing exercise taxes and prices on tobacco products may be recommended in Sudan [24].

The prevalence of low physical activity $(21.3 \%)$ in this survey was lower than in a study in Khartoum state, Sudan, (53.8\%) [14]. The proportion of raised total cholesterol (13.6\%), and diabetes $(5.9 \%)$ in this study was lower than in the 2005-2006 Khartoum State STEPS survey (raised total cholesterol 19.8\% and diabetes 19.8\%) [10] in four main cities of the River Nile State, north Sudan (diabetes 19.1\%) [12], in 
the Northern State and River Nile State (diabetes 18.7\%) [13], but higher than in the Malawi STEPS survey (raised cholesterol: $8.7 \%$ and raised fasting blood glucose: 5.6\%) [17] and the Kenya STEPS survey (high blood total cholesterol: $10.1 \%$ and diabetes: $2.6 \%$ [16].

Some of the found NCD risk factors differed by sex. Current tobacco use and heavy episodic drinking was significantly higher in men than in women, while low physical activity, general overweight/obesity, raised total cholesterol and diabetes was significantly higher in women than in men. In the Kenya STEPS survey daily tobacco and harmful alcohol use was also more prevalent in men than in women, obesity and raised total cholesterol was more common among women than men were [16]. Similarly, in the Malawi STEPS survey, the prevalence of alcohol use and tobacco smoking was higher in men than women, and overweight/obesity and raised cholesterol were higher in women than men were [17]. The higher prevalence of overweight/obesity in women may be attributed to "in Sudan, obesity is associated with beauty. Furthermore, some young women in Sudan use steroids to gain weight and refuse to take metformin because it is associated with weight loss." [25]. These gender differences in the prevalence of different individual NCD risk factors as well as multiple NCD risk factors need to be taking into account in NCD health promotion interventions [17].

This study was limited because of the self-report of the interview data as well as its cross-sectional design. Further, the public use dataset of the Sudan 2016 STEPS survey did not include some of the variables, such as region and state, which could therefore not be included in the analysis.

\section{Conclusion}

The study found among a nationally representative population of 18 to 69 years in Sudan that almost one in three participants had three or more NCD risk factors. Several associated factors were identified for multiple NCD risk factors, including older age, male sex, urban residence, higher household income and among women higher level of education, which can assist in guiding interventions to prevent multiple NCD risk factors in the Sudanese population. Considering the clustered nature of NCD risk factors, interventions are needed that target multiple, in particular modifiable, NCD risk factors.

\section{Abbreviations}

BMI: Body Mass Index; BP: Blood Pressure; HDL: High-density lipoprotein; NCD: Non-communibale diseases; STEPS: STEPwise approach to surveillance; STATA: Statistics and data

\section{Declarations}

\section{Acknowledgements}

"The data source, the World Health Organization NCD Microdata Repository (URL: https://extranet.who.int/ncdsmicrodata/index.php/catalog), is hereby acknowledged." 


\section{Authors' contributions}

"All authors fulfill the criteria for authorship. SP and KP conceived and designed the research, performed statistical analysis, drafted the manuscript and made critical revision of the manuscript for key intellectual content. All authors read and approved the final version of the manuscript and have agreed to authorship and order of authorship for this manuscript."

\section{Funding}

No funding was received.

\section{Availability of data and materials}

The data on which this analysis were based are publicly available at the World Health Organization NCD Microdata Repository: URL: https://extranet.who.int/ncdsmicrodata/index.php/catalog.

\section{Ethics approval and consent to participate}

This study was approved by the national ethical committee at Federal Ministry of Health, Sudan [23]. Verbal informed consent was obtained from all participants [23].

\section{Consent for publication}

Not applicable.

\section{Competing interests}

The authors declare that they have no competing interests.

\section{References}

1. World Health Organization (WHO) Sudan: Noncommunicable Diseases (NCD) Country Profiles, 2018. URL: https://www.who.int/nmh/countries/sdn_en.pdf?ua=1

2. World Health Organization (WHO) Noncommunicable diseases, 2018. URL: https://www.who.int/news-room/fact-sheets/detail/noncommunicable-diseases

3. Nyirenda MJ. Non-communicable diseases in sub-Saharan Africa: understanding the drivers of the epidemic to inform intervention strategies. Int Health. 2016;8(3):157-158.

doi:10.1093/inthealth/ihw021

4. World Health Organization (WHO). Non-communicable diseases. URL: http://www.emro.who.int/noncommunicable-diseases/publications/burden-of-noncommunicablediseases-in-the-eastern-mediterranean-region.html

5. Ahmed MH, Ali YA, Awadalla H, Elmadhoun WM, Noor SK, Almobarak AO. Prevalence and trends of obesity among adult Sudanese individuals: Population based study. Diabetes Metab Syndr. 2017;11 
Suppl 2:S963-S967. doi:10.1016/j.dsx.2017.07.023

6. Omar SM, Taha Z, Hassan AA, Al-Wutayd O, Adam I. Prevalence and factors associated with overweight and central obesity among adults in the Eastern Sudan. PLoS One. 2020;15(4):e0232624. Published 2020 Apr 30. doi:10.1371/journal.pone.0232624

7. Ali I, Behairy H, Abugroun A, Beaney T, Kobeissi E, Abdalla A, Mohamed A, Wagialla N, Medani SS, Ismail EM, Hassan DA, Altahir F, Abdelrahim M, Gdoor A, Mohamed I, Elnour S, Poulter NR. May Measurement Month 2017: an analysis of blood pressure screening in Sudan-Northern Africa and Middle East. Eur Heart J Suppl. 2019;21(Suppl D):D111-D114. doi: 10.1093/eurheartj/suz071.

8. Omar SM, Musa IR, Osman OE, Adam I. Prevalence and associated factors of hypertension among adults in Gadarif in eastern Sudan: a community-based study. BMC Public Health. 2020;20(1):291. doi:10.1186/s12889-020-8386-5

9. Bushara SO, Noor SK, Ibraheem AA, Elmadhoun WM, Ahmed MH. Prevalence of and risk factors for hypertension among urban communities of North Sudan: Detecting a silent killer. J Family Med Prim Care. 2016;5(3):605-610. doi:10.4103/2249-4863.197317

10. World Health Organization (WHO). Khartoum State/Sudan: STEPS survey 2005-2006. URL: https://www.who.int/ncds/surveillance/steps/STEPS_FactSheet_Sudan.pdf

11. Awadalla H, Elmak NE, El-Sayed EF, Almobarak AO, Elmadhoun WM, Osman M, Noor SK, Ahmed MH. Hypertension in Sudanese individuals and associated risk factors: the critical intersection between salt and sugar intake. Cardiovasc Diagn Ther. 2018 Aug;8(4):432-438. doi:

12. Elmadhoun WM, Noor SK, Ibrahim AA, Bushara SO, Ahmed MH. Prevalence of diabetes mellitus and its risk factors in urban communities of north Sudan: Population-based study. J Diabetes. 2016;8(6):839-846. doi:10.1111/1753-0407.12364

13. Eltom MA, Babiker Mohamed AH, Elrayah-Eliadarous H, Yassin K, Noor SK, Elmadhoun WM, Ahmed $\mathrm{MH}$. Increasing prevalence of type 2 diabetes mellitus and impact of ethnicity in north Sudan. Diabetes Res Clin Pract. 2018;136:93-99. doi: 10.1016/j.diabres.2017.11.034.

14. Khalil S, Almobarak AO, Awadalla H, Elmadhoun WM, Noor SK, Sulaiman AA, Ahmed MH. Low levels of physical activity in Sudanese individuals with some features of metabolic syndrome: Population based study. Diabetes Metab Syndr. 2017;11 Suppl 2:S551-S554. doi: 10.1016/j.dsx.2017.04.003.

15. Khalid FA, Ali AKM, Ali SA, Mosmar ZYA, Salih SSM, Salman TK, et al. Households' dietary habits and food consumption patterns in Hamishkoreib locality, Kassala State, Sudan. J Ethnic Foods. 2017;4(3): 181-186, https://doi.org/10.1016/j.jef.2017.08.009.

16. Wekesah FM, Nyanjau L, Kibachio J, et al. Individual and household level factors associated with presence of multiple non-communicable disease risk factors in Kenyan adults. BMC Public Health. 2018;18(Suppl 3):1220. doi:10.1186/s12889-018-6055-8

17. Msyamboza KP, Ngwira B, Dzowela T, et al. The burden of selected chronic non-communicable diseases and their risk factors in Malawi: nationwide STEPS survey. PLoS One. 2011;6(5):e20316. doi:10.1371/journal.pone.0020316 
18. Wesonga R, Guwatudde D, Bahendeka SK, Mutungi G, Nabugoomu F, Muwonge J. Burden of cumulative risk factors associated with non-communicable diseases among adults in Uganda: evidence from a national baseline survey. Int J Equity Health. 2016;15(1):195. doi:10.1186/s12939016-0486-6

19. Aryal KK, Mehata S, Neupane S, et al. The Burden and Determinants of Non Communicable Diseases Risk Factors in Nepal: Findings from a Nationwide STEPS Survey. PLoS One. 2015;10(8):e0134834. doi:10.1371/journal.pone.0134834

20. Zaman MM, Bhuiyan MR, Karim MN, et al. Clustering of non-communicable diseases risk factors in Bangladeshi adults: An analysis of STEPS survey 2013. BMC Public Health. 2015;15:659. doi:10.1186/s12889-015-1938-4

21. Rafique I, Saqib MAN, Munir MA, et al. Prevalence of risk factors for noncommunicable diseases in adults: key findings from the Pakistan STEPS survey. East Mediterr Health J. 2018;24(1):33-41.

22. Pelzom D, Isaakidis $P, O \circ M M$, Gurung MS, Yangchen P. Alarming prevalence and clustering of modifiable noncommunicable disease risk factors among adults in Bhutan: a nationwide crosssectional community survey. BMC Public Health. 2017;17(1):975. doi:10.1186/s12889-017-4989-x

23. Federal Ministry of Health, Sudan. Sudan STEP-wise survey for non-communicable diseases risk factors, 2016 report. URL: https://extranet.who.int/ncdsmicrodata/index.php/catalog/438

24. American Cancer Society. Tobacco Atlas: Sudan. URL: https://files.tobaccoatlas.org/wpcontent/uploads/pdf/sudan-country-facts-en.pdf

25. Assaad Khalil SH, Abdelaziz SI, Al Shammary A, Al Zahrani A, Amir A, Elkafrawy N, Hassoun AA, Hostalek U, Jahed A, Jarrah N, Mrabeti S, Paruk I, Zilov AV. Prediabetes management in the Middle East, Africa and Russia: Current status and call for action. Diab Vasc Dis Res. 2019;16(3):213-226. doi: $10.1177 / 1479164118819665$.

\section{Tables}

Table 1: Sample and non-communicable diseases risk factors among 18-69 year-old persons in Sudan, $2016(\mathrm{~N}=7722)$ 


\begin{tabular}{|llllll|}
\hline Variable & Sample & All & Male & Female & $\begin{array}{l}\text { Sex } \\
\text { difference }\end{array}$ \\
& $\begin{array}{l}\text { Unweighted } \\
\text { number }\end{array}$ & $\%$ & $\%$ & $\%$ & p-value \\
\hline
\end{tabular}

\section{Socio-demographics}

Age in years

$\begin{array}{llllll}18-34 & 3454 & 57.7 & 58.9 & 56.2 & 0.094 \\ 35-49 & 2474 & 26.5 & 25.3 & 28.0 & \\ 50-69 & 1794 & 15.8 & 15.9 & 15.8 & \end{array}$

Sex

Female

Male

Education

Cannot read or write

$\leq$ Primary

>Primary

Household income (Sudanese Pounds)

$\leq 500$

501 to $\leq 1000$

1001 to $\leq 2000$

$>2000$

Do not know

Marital status

Never married

Married

Separated/divorced/widowed

Employment status

Self-employed/non-

paid/student/unemployed (able to work)

Government employee

Non-government employee
5016

2707

3272

2481

1952

1326

2632

1949

727

1025

1205

5871

634

558

858

2389

Page $11 / 16$
64.9

35.1

$\begin{array}{llll}34.0 & 24.2 & 45.7 & <0.001\end{array}$

$\begin{array}{lll}34.2 & 39.7 & 27.6\end{array}$

$\begin{array}{lll}31.8 & 36.1 \quad 26.7\end{array}$

$\begin{array}{llll}18.9 & 20.4 & 17.2 & 0.073\end{array}$

$\begin{array}{lll}32.8 & 33.2 & 32.5\end{array}$

$24.1 \quad 23.7 \quad 24.6$

$\begin{array}{lll}10.5 & 10.5 & 10.5\end{array}$

$\begin{array}{lll}13.6 & 12.2 & 15.3\end{array}$

$\begin{array}{llll}30.3 & 40.0 & 18.5 & <0.001\end{array}$

$\begin{array}{lll}64.8 & 58.4 & 72.4\end{array}$

$\begin{array}{lll}4.9 & 1.5 & 9.1\end{array}$ 


\begin{tabular}{|llllll|}
\hline $\begin{array}{l}\text { Homemaker } \\
\text { Retired/unemployed (unable to work) }\end{array}$ & 3677 & 31.4 & 1.9 & 67.0 & \\
\hline Residence & 218 & 2.2 & 2.6 & 1.7 & \\
$\quad \begin{array}{l}\text { Rural } \\
\text { Urban }\end{array}$ & 5129 & 62.9 & 62.4 & 63.5 & 0.563 \\
\hline Non-communicable diseases risk factors & 2593 & 37.1 & 37.6 & 36.5 & \\
\hline $\begin{array}{l}\text { Fruit and vegetable intake (<5 } \\
\text { servings/day) }\end{array}$ & 410 & & & & \\
\hline Low physical activity & 1827 & 21.3 & 17.8 & 25.5 & $<0.001$ \\
\hline Current tobacco use & 830 & 15.7 & 28.1 & 0.7 & $<0.001$ \\
\hline Heavy episodic drinking & 78 & 1.7 & 3.0 & 0.2 & $<0.001$ \\
\hline Diabetes & 515 & 5.9 & 5.0 & 6.8 & 0.014 \\
\hline Hypertension & 2710 & 31.6 & 31.1 & 32.1 & 0.495 \\
\hline Raised total cholesterol & 1229 & 13.6 & 8.8 & 19.5 & $<0.001$ \\
\hline General overweight/obesity & 2455 & 28.0 & 22.5 & 35.2 & $<0.001$ \\
\hline
\end{tabular}

Table 2: Proportion of multiple non-communicable diseases risk factors (NCDs) among 18-69 year-old persons in Sudan, 2016 


\begin{tabular}{|c|c|c|c|c|c|c|c|c|c|}
\hline \multirow[t]{3}{*}{ Variable } & \multicolumn{3}{|l|}{ All } & \multicolumn{3}{|l|}{ Men } & \multicolumn{3}{|c|}{ Women } \\
\hline & \multicolumn{3}{|c|}{$\begin{array}{l}\text { Number of NCD risk } \\
\text { factors }\end{array}$} & \multicolumn{3}{|c|}{$\begin{array}{l}\text { Number of NCD risk } \\
\text { factors }\end{array}$} & \multicolumn{3}{|c|}{$\begin{array}{l}\text { Number of NCD risk } \\
\text { factors }\end{array}$} \\
\hline & $0-1$ & 2 & $3-8$ & $0-1$ & 2 & $3-8$ & $0-1$ & 2 & $3-8$ \\
\hline & $\%$ & $\%$ & $\%$ & $\%$ & $\%$ & $\%$ & $\%$ & $\%$ & $\%$ \\
\hline All & 34.2 & 33.5 & 32.4 & 33.3 & 36.3 & 30.4 & 35.3 & 29.9 & 34.8 \\
\hline \multicolumn{10}{|l|}{ Age (years) } \\
\hline $18-34$ & 43.8 & 35.7 & 20.4 & 40.8 & 38.2 & 21.0 & 48.1 & 32.3 & 19.6 \\
\hline $35-49$ & 25.2 & 32.8 & 42.0 & 25.5 & 36.7 & 37.8 & 24.8 & 28.5 & 46.7 \\
\hline $50-69$ & 15.7 & 26.8 & 57.5 & 17.9 & 28.6 & 53.5 & 13.1 & 24.5 & 62.4 \\
\hline p-value & \multicolumn{3}{|c|}{$<0.001$} & \multicolumn{3}{|c|}{$<0.001$} & \multicolumn{3}{|c|}{$<0.001$} \\
\hline \multicolumn{10}{|l|}{ Gender } \\
\hline Male & 35.3 & 29.9 & 34.8 & & & & & & \\
\hline Female & 33.3 & 36.3 & 30.4 & & & & & & \\
\hline$p$-value & \multicolumn{3}{|c|}{$<0.001$} & & & & & & \\
\hline \multicolumn{10}{|l|}{ Education } \\
\hline Cannot read or write & 32.8 & 36.7 & 30.5 & 28.8 & 42.9 & 28.3 & 35.5 & 32.5 & 32.1 \\
\hline$\leq$ Primary & 36.5 & 32.4 & 31.1 & 35.3 & 34.2 & 30.5 & 38.7 & 29.0 & 32.3 \\
\hline >Primary & 33.2 & 31.3 & 35.5 & 34.2 & 34.0 & 31.8 & 31.6 & 26.5 & 41.9 \\
\hline$p$-value & \multicolumn{3}{|c|}{0.041} & \multicolumn{3}{|c|}{0.103} & \multicolumn{3}{|c|}{$<0.001$} \\
\hline \multicolumn{10}{|l|}{ Marital status } \\
\hline Never married & 45.7 & 34.0 & 20.3 & 44.7 & 35.7 & 19.6 & 48.4 & 29.6 & 22.0 \\
\hline Married & 29.1 & 34.0 & 36.9 & 25.8 & 36.6 & 37.6 & 32.8 & 31.1 & 36.1 \\
\hline Separated/divorced/widowed & 25.8 & 24.0 & 50.2 & 23.7 & 39.1 & 37.2 & 26.3 & 20.8 & 52.9 \\
\hline $\mathrm{p}$-value & \multicolumn{3}{|c|}{$<0.001$} & \multicolumn{3}{|c|}{$<0.001$} & \multicolumn{3}{|c|}{$<0.001$} \\
\hline \multicolumn{10}{|l|}{ Employment status } \\
\hline $\begin{array}{l}\text { Self-employed/non- } \\
\text { paid/student/unemployed } \\
\text { (able to work) }\end{array}$ & 24.5 & 30.8 & 44.7 & 22.9 & 30.6 & 46.5 & 27.8 & 31.3 & 41.0 \\
\hline Government employee & 27.0 & 36.0 & 37.0 & 25.0 & 37.5 & 37.5 & 37.6 & 28.3 & 34.2 \\
\hline Non-government employee & 40.2 & 35.5 & 24.3 & 38.9 & 37.0 & 24.1 & 44.9 & 29.7 & 25.4 \\
\hline
\end{tabular}




\begin{tabular}{|c|c|c|c|c|c|c|c|c|c|}
\hline Homemaker & 33.2 & 29.8 & 37.0 & 38.6 & 26.8 & 34.5 & 33.0 & 29.9 & 37.1 \\
\hline $\begin{array}{l}\text { Retired/unemployed (unable } \\
\text { to work) }\end{array}$ & 11.5 & 30.9 & 57.6 & 4.1 & 31.0 & 64.8 & 25.7 & 30.5 & 43.8 \\
\hline p-value & \multicolumn{3}{|c|}{$<0.001$} & \multicolumn{3}{|c|}{$<0.001$} & \multicolumn{3}{|c|}{$<0.001$} \\
\hline \multicolumn{10}{|l|}{ Residence } \\
\hline Rural & 38.2 & 35.6 & 26.1 & 36.0 & 38.5 & 25.5 & 41.1 & 32.0 & 27.0 \\
\hline Urban & 27.4 & 29.9 & 42.7 & 28.7 & 32.6 & 38.8 & 25.8 & 26.4 & 47.8 \\
\hline$p$-value & \multicolumn{3}{|c|}{$<0.001$} & \multicolumn{3}{|c|}{$<0.001$} & \multicolumn{3}{|c|}{$<0.001$} \\
\hline \multicolumn{10}{|l|}{$\begin{array}{l}\text { Household income (Sudanese } \\
\text { Pounds) }\end{array}$} \\
\hline$\leq 500$ & 40.6 & 33.8 & 25.6 & 42.0 & 35.6 & 22.3 & 38.5 & 31.0 & 30.5 \\
\hline 501 to $>1000$ & 36.8 & 31.8 & 31.3 & 36.5 & 34.4 & 29.1 & 37.3 & 28.5 & 34.2 \\
\hline 1001 ro $<2000$ & 28.0 & 34.6 & 37.4 & 25.2 & 37.5 & 37.3 & 31.5 & 31.0 & 49.9 \\
\hline$>2000$ & 25.2 & 31.4 & 43.4 & 26.5 & 35.4 & 38.1 & 23.6 & 26.6 & 25.2 \\
\hline Do not know & 37.8 & 35.6 & 26.6 & 32.7 & 39.5 & 27.9 & 43.4 & 31.4 & 34.9 \\
\hline$p$-value & \multicolumn{3}{|c|}{$<0.001$} & \multicolumn{3}{|c|}{$<0.001$} & \multicolumn{3}{|c|}{$<0.001$} \\
\hline
\end{tabular}

Table 3: Associations with multiple non-communicable diseases risk factors among 18-69 year-old persons in Sudan, 2016 


\begin{tabular}{|c|c|c|c|}
\hline Variable & All & Men & Women \\
\hline & AOR $(95 \% \mathrm{Cl})$ & AOR $(95 \% \mathrm{Cl})$ & $\operatorname{AOR}(95 \% \mathrm{Cl})$ \\
\hline \multicolumn{4}{|l|}{ Age in years } \\
\hline $18-34$ & 1 (Reference) & 1 (Reference) & 1 (Reference) \\
\hline $35-49$ & $\begin{array}{l}2.04(1.72 \\
2.43)^{\star \star \star}\end{array}$ & $\begin{array}{l}1.45(1.09 \\
1.93)^{\star}\end{array}$ & $\begin{array}{l}2.73(2.29 \\
3.26)^{\star \star \star}\end{array}$ \\
\hline $50-69$ & $\begin{array}{l}3.52(2.88 \\
4.31)^{\star \star \star}\end{array}$ & $\begin{array}{l}2.26(1.66 \\
3.09)^{\star \star \star}\end{array}$ & $\begin{array}{l}5.45(4.29 \\
6.94)^{\star \star \star *}\end{array}$ \\
\hline \multicolumn{4}{|l|}{ Sex } \\
\hline Female & 1 (Reference) & - & -- \\
\hline Male & $\begin{array}{l}1.21(1.00 \\
1.46)^{\star}\end{array}$ & & \\
\hline \multicolumn{4}{|l|}{ Education } \\
\hline Cannot read or write & 1 (Reference) & 1 (Reference) & 1 (Reference) \\
\hline$\leq$ Primary & $\begin{array}{l}1.02(0.85 \\
1.22)\end{array}$ & $\begin{array}{l}0.97(0,74 \\
1.28)\end{array}$ & $\begin{array}{l}1.07(0.88 \\
1.30)\end{array}$ \\
\hline$>$ Primary & $\begin{array}{l}1.01(0.81 \\
1.26)\end{array}$ & $\begin{array}{l}0.84(0.60 \\
1.15)\end{array}$ & $\begin{array}{l}1.38(1.06 \\
1.80)^{\star}\end{array}$ \\
\hline \multicolumn{4}{|l|}{ Marital status } \\
\hline Never married & 1 (Reference) & 1 (Reference) & 1 (Reference) \\
\hline \multirow{2}{*}{$\begin{array}{l}\text { Married } \\
\text { Separated/divorced/widowed }\end{array}$} & $\begin{array}{l}1.51(1.22 \\
1.87)^{\star \star \star}\end{array}$ & $\begin{array}{l}1.84(1.34 \\
2.52)^{\star \star \star}\end{array}$ & $\begin{array}{l}1.43(1.11 \\
1.84)^{\star \star}\end{array}$ \\
\hline & $\begin{array}{l}1.74(1.22 \\
2.47)^{\star \star}\end{array}$ & $\begin{array}{l}1.67(0.86 \\
3.26)\end{array}$ & $\begin{array}{l}1.55(1.04 \\
2.29)^{\star}\end{array}$ \\
\hline \multicolumn{4}{|c|}{ Household income (Sudanese Pounds) } \\
\hline$\leq 500$ & 1 (Reference) & 1 (Reference) & 1 (Reference) \\
\hline 501 to $\leq 1000$ & $\begin{array}{l}1.19(0.95 \\
1.48)\end{array}$ & $\begin{array}{l}1.30(0.95 \\
1.78)\end{array}$ & $\begin{array}{l}1.01(0.79 \\
1.28)\end{array}$ \\
\hline$>2000$ & $\begin{array}{l}1.61(1.26 \\
2.06)^{\star \star \star}\end{array}$ & $\begin{array}{l}2.00(1.41 \\
2.84)^{\star \star \star}\end{array}$ & $\begin{array}{l}1.19(0.91 \\
1.56)\end{array}$ \\
\hline \multirow[t]{2}{*}{ Do not know } & $\begin{array}{l}1.75(1.28 \\
2.38)^{\star \star \star}\end{array}$ & $\begin{array}{l}2.01(1.27 \\
3.19)^{\star \star}\end{array}$ & $\begin{array}{l}1.36(1.01 \\
1.82)^{\star}\end{array}$ \\
\hline & $\begin{array}{l}1.28(0.96, \\
1.71)\end{array}$ & $\begin{array}{l}1.78(1.24 \\
2.57)^{\star \star}\end{array}$ & $\begin{array}{l}0.88(0.62, \\
1.24)\end{array}$ \\
\hline
\end{tabular}


Self-employed/non-paid/student/unemployed (able to work)

Government employee

Non-government employee

1 (Reference) 1 (Reference) 1 (Reference)

Homemaker

$1.43(1.06$

$1.93)^{*}$

$1.82(1.20$,

$0.93(0.62$.

$1.46(1.16$

$1.83)^{\star \star \star}$

$2.77)^{\star \star}$

1.42)

Retired/unemployed (unable to work)

1.59 (1.22, $\quad 1.20(0.80$,

2.07) $\left.)^{\star \star \star} \quad 1.80\right)$

$\begin{array}{lll}1.32(1.08, & 1.16(0.50, & 1.22(0.97, \\ 1.63)^{\star \star} & 2.73) & 1.54) \\ 2.13(1.47, & 3.46(2.06, & 1.25(0.74, \\ 3.07)^{\star \star \star} & 5.83)^{\star \star \star} & 2.11)\end{array}$

Residence

Rural

1 (Reference) 1 (Reference) 1 (Reference)

Urban

$1.86(1.49$

$2.32)^{\star \star \star}$

$1.79(1.32$

$3.41)^{\star \star \star}$

$1.90(1.52$

$2.37)^{\star \star \star}$

AOR=Adjusted Odds Ratio; $\mathrm{Cl}=$ Confience Interval; $\quad * \star * \mathrm{p}<0.001 ;{ }^{*} \mathrm{p}<0.01 ; * \mathrm{P}<0.05$

\section{Figures}

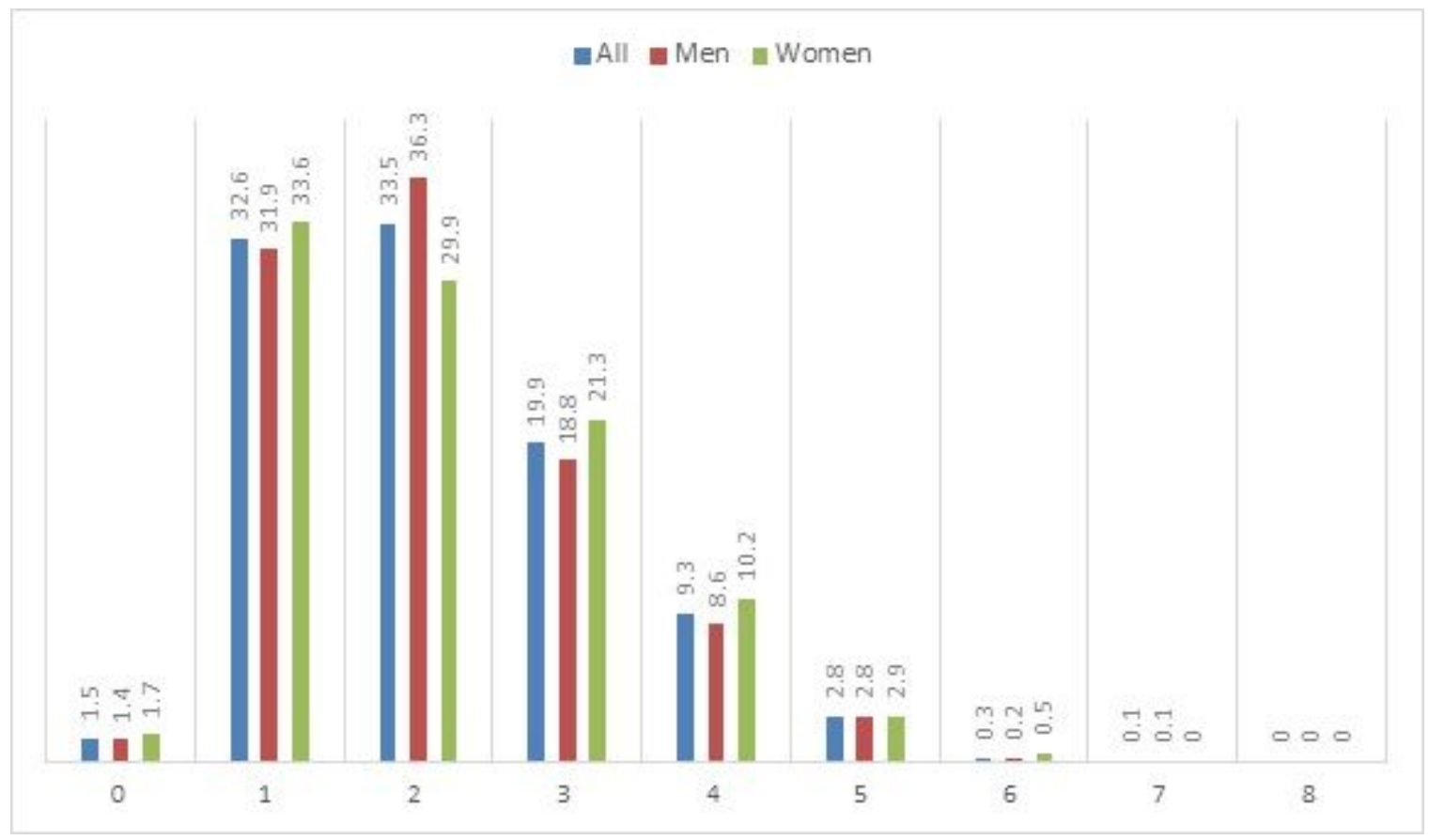

Figure 1

Frequency of non-communicable diseases risk factors among adults in Sudan 